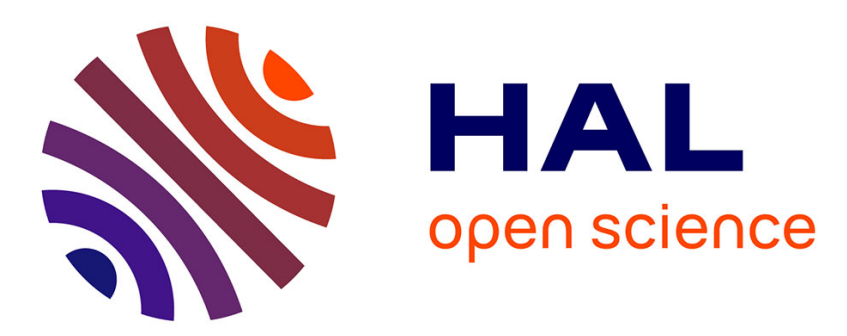

\title{
The Implementation Gap: Environmental Rhetoric Versus Reality in Lao Cai, Vietnam \\ Gwenn Pulliat
}

\section{To cite this version:}

Gwenn Pulliat. The Implementation Gap: Environmental Rhetoric Versus Reality in Lao Cai, Vietnam. Daniere, Amrita G.; Garschagen, Matthias. Urban Climate Resilience in Southeast Asia, Springer, pp.201-222, 2019, The Urban Book Series, 978-3-319-98968-6. 10.1007/978-3-319-989686_10. hal-02122207

\section{HAL Id: hal-02122207 https://hal.science/hal-02122207}

Submitted on 15 May 2019

HAL is a multi-disciplinary open access archive for the deposit and dissemination of scientific research documents, whether they are published or not. The documents may come from teaching and research institutions in France or abroad, or from public or private research centers.
L'archive ouverte pluridisciplinaire HAL, est destinée au dépôt et à la diffusion de documents scientifiques de niveau recherche, publiés ou non, émanant des établissements d'enseignement et de recherche français ou étrangers, des laboratoires publics ou privés. 
DRAFT. G. Pulliat, The Implementation Gap. April 2018.

Urban Climate Resilience in Southeast Asia.

Chapter 10:

\section{The Implementation Gap: Reality vs. Environmental Rhetoric in Lao Cai, Vietnam}

\section{Gwenn Pulliat ${ }^{1}$}

\section{Abstract}

This chapter examines the implementation of environmental policy in a rapidly growing secondary city in Vietnam. I argue that despite official discourse around the importance of protecting the physical environment and the promotion of a more climate resilient form of urban development, and despite the endorsement of adequate regulations to do so, little is actually being done. The urban development pattern remains highly resourceconsuming and the ambition to foster a large, modernized city seems to overshadow any environmental objectives. Although local and national authorities are quick to focus on the lack of means to actually implement environmentally sensitive policy, they actively obscure the preference given to economic growth over the environment and do not appear to consider the environmental and social outcomes of their economic policies.

This study draws upon a case-study of Lao Cai. Lao Cai province as a whole is recognized as one of the most important ecological regions in

${ }^{1}$ CNRS (French National Center for Scientific Research)

Formerly postdoctoral fellow, Munk School of Global Affairs, University of Toronto 
DRAFT. G. Pulliat, The Implementation Gap. April 2018.

Vietnam, but also one of the most vulnerable to climate hazards. The province has recently adopted an Action Plan for climate change adaptation. Meanwhile, however, the national authorities intend to promote Lao Cai as a major secondary city on the main route from China to Hanoi. In a context of rapid, strategic, state-driven urban development, I identify three main obstacles to effective implementation of environmental and climate change policies: (1) the preeminence of economic growth over any environmental goal, (2) the under-enforcement of existing regulations and (3) a failure of environmental governance. Meanwhile, environmental risks management is mainly based on the reinforcement of defensive infrastructures (such as the river embankment) and the displacement of exposed people. These actions are likely inefficient in a context of increased major hazards and which might put great pressure on displaced residents' livelihoods. I conclude with a discussion of the discourse-implementation disconnect.

\section{Introduction}

In October 2017, the Hanoi-Lao Cai railway, one of the most popular railways for carrying tourists from the capital city of Hanoi in Vietnam to the renowned station of Sapa as well as for transporting large amounts of merchandise from China to the Red River delta, was blocked by a landslide for several days (Nhan Dan 2017). In September 2017, in Lao Cai city, 46 houses were flooded (VNS 2017). In 2016, 10 people died, swept away by a flood, during the rainy season (VNS 2016). These are only a few examples of the environmental disasters occurring every year in the region. Indeed, Lao Cai province, located in the Northern region of Vietnam, is the source of many news stories based on weather-related events. Landslides, flashfloods, major storms and cold waves, to name a few: the region is recognized as one of the most exposed to major hazards in the country.

At the same time, the Northern highlands region of Vietnam is wellknown for its ecological wealth. The province of Lao Cai has long been singled out for particular attention in terms of efforts to protect its forests, unique landscapes and ecosystems. Therefore, the consequences of environmental and climate changes in these highlands are critical and this explains why Lao Cai province is a focal point of the national environmental policies.

In addition, however, Lao Cai is located at the border with China. Actually, it is the main point of entry between the two countries and this has been reinforced by the construction of a highway between Hanoi and Hai Phong (the main port of the northern part of the country) and the Yunnan province in China. Hence, the Vietnamese government considers the 
DRAFT. G. Pulliat, The Implementation Gap. April 2018.

development of the city as highly strategic. The pace of urbanization has been rapid : studying the land use changes in the Northern half of the province, Trincsi, Pham and Turner (2014) found that the build-up area in 2009 is six times larger than that in 1999 (shifting from 12.7 sq.km to 79.6 sq.km, mainly along the Red River). In a context of rapid and strategic urban development, it is important to assess how well the environmental and climate adaptation policies in the region are actually being implemented.

This antagonism between the acknowledged need for environmental protection and climate adaptation on the one hand, and the urban development on the other hand, is unique neither to Lao Cai nor to Vietnam on its whole. In Southeast Asia, the deltas and coastal areas are considered as the most vulnerable to climate change (Yusuf and Francisco 2009; Neil Adger 1999; Birkmann et al. 2010), while also being the most densely populated regions. The dilemma is remarkably acute. As a consequence, the infrastructure of megacities located in those areas, which host several million residents and major political, economic, cultural centers, are given priority. Most of the political and environmental action to mitigate the impacts of climate change tends to concentrate there.

Nonetheless, climate change also affects other regions. Secondary cities (also called medium cities, or intermediate cities), which comprise urban centers that play a local and regional role in the spatial organization of a country, with a sub-national leadership (Roberts and Hohmann 2014), often combine rapid urban growth with much lower levels of public and private investment than major cities. In Southeast Asia, secondary cities absorb a significant part of the national urban population growth, be it from rural-urban migrations or from natural growth. But they often grow unnoticed, gaining little attention of national authorities, planners and scholars. They constitute a wide range of so-called "ordinary cities" (Amin and Graham 1997; Robinson 2006). Hence, they may pose important challenges in the future. Furthermore, in the field of environmental protection, these cities often face inefficient legislation and governance (Adger 2001). As such, they may be more vulnerable than larger cities to climate change impacts in many ways: their demographic growth increases the number of people potentially at risk and rapid change in the uses of land may affect their exposure to hazards as the same time as they lack capacity to implement adaptive policies. Consequently, growing secondary cities are of particular interest when looking at climate resilience building policies.

\section{Goal and methods}

The goal of this study is to explore how the national prioritization of climate change policies translates into action at the local scale. Has the political discourse around climate change and the emphasis put on environmental policies impacted local urban planning practices and 
outcomes? To explore this core question, I conducted fieldwork in July 2017 in Lao $\mathrm{Cai}^{2}$. It consisted of two interconnected sets of interviews:

- 23 semi-structured interviews with officials from various bureaus working on urban planning, land use management and environmental issues at Province, City and local People's Committees; interviewees were identified to cover most of the bureaus involved in environmental and climate policies across scales (except for the national scale);

- 45 comprehensive interviews with residents in two wards of Lao Cai city covering residents' livelihoods and daily experience of the change in their environment. The selection process combined random selection in the wards and targeted interviews based on recommendations from either households' representatives or previous interviewees ${ }^{3}$.

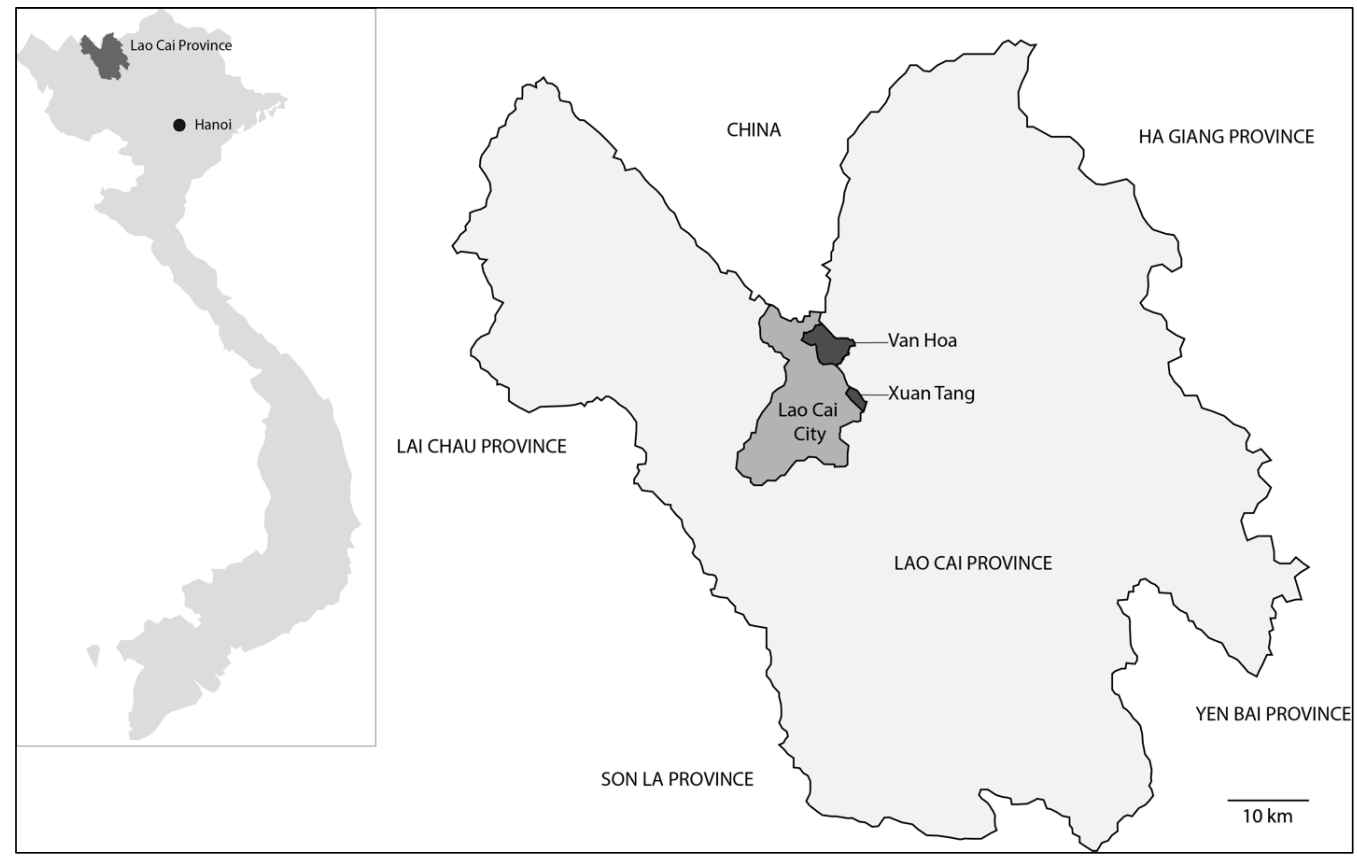

Figure 1 Location of investigated wards. (C) G. Pulliat

2 This research was conducted during my postdoctoral fellowship at the University of Toronto and was funded by the Social Sciences and Humanities Research Council (SSHRC) through the Urban Climate Resilient on South East Asia (UCRSEA) partnership.

${ }^{3}$ In Vietnam, every ward is sub-divided in several neighborhoods and one resident from each of them is in charge of the inhabitants. They are the first person that people refer to as they help residents in various administrative tasks. As a result, they often have a very keen knowledge of their ward and its inhabitants and are, therefore, unavoidable gatekeepers and a valuable point of entry to the field. 
DRAFT. G. Pulliat, The Implementation Gap. April 2018.

The two wards included are both located at the fringe of the urban core and exposed to various hazards (landslides, floods in particular): Xuan Tang and Van Hoa (cf. Figure 1).

While the first group of interviews was designed to shed light on the actual governance of the climate change adaptation and environmental policies, the second group were meant to complement the information gleaned from the public sector and provide a narrative of the changes occurring in the city and their impact on residents' daily life.

\section{A contribution to the UCRSEA framework}

The discrepancy between climate urgency and (more or less) largescale urban planning is found in many cities across Southeast Asia. Special Economic Zones are burgeoning even in areas that are prone to climate change impacts, such as in Dawei, Myanmar (Chapter x). Intense urban development is witnessed in many secondary cities and begs questions about their ability to response to natural hazards, as illustrated with the floods in Ninh Binh, Vietnam (Chapter y). The high expectations on cities in terms of short-term economic growth often lead to non-sustainable solutions: the case of Cambodia (Asif, Marschke, and Ngin 2017) provides a powerful example of the disconnect between short-term goals and the long-term need for climate adaptation. Not unexpectedly, the situation of Lao Cai exhibits challenges that are found in many other contexts.

Focusing on how climate policies are implemented, this study primarily speaks to the second UCRSEA framing question, which explores climate adaptation governance. Drawing upon evidence from the field, I critically explore environmental governance within the developmental pattern that Vietnamese authorities have adopted. Additionally, since it highlights the changes in residents' livelihoods resulting from urban development and risks management, this study contributes to the analysis of the linkages between individuals' well-being and climate policies - a topic that relates to the third UCRSEA core question (How can we strengthen the agency of individuals, groups and institutions to improve economic, physical and social well-being in urban areas, particularly in response to climate change?).

\section{A brief overview of the literature}

Studies on climate policies in cities are abundant (see for instance Hunt and Watkiss (2011) for a review), as are assessments of policy implementation (a review can be found in Berrang-Ford et al. (2011)). However, according to Ryan (2015), these studies tend to be descriptive and fragmented. Often, climate policy implementation is considered from a specific sector (e.g., energy sector). Conversely, my research focuses on climate policies as a whole, and scrutinizes the process of implementation 
itself - i.e. the translation of national goals and commitments into concrete actions. A few other authors have explored this translation process. Based on two case studies, Dupuis and Knoepfel (2013) argue that adaptation policies face an "implementation deficit", because of the lack of effective actions conducted by state authorities. Other studies point to various factors related to observed deficits in implementation: lack of funding (ICLEI 2017; Mol 2009; Anguelovski and Carmin 2011), limited priority given to these policies (Chan et al. 1995; ICLEI 2017; Mitchell and Laycock 2017), difficult integration of climate policies to sectorial policies (Puppim de Oliveira 2013). Drawing upon this literature, my research contributes to the body of knowledge on the implementation gap, while adding two distinguishing perspectives:

- I specifically address the case of secondary cities,

- It is based on two sets of interviews conducted at various scales which draw attention to the nexus between the governance of environmental policies and its spatial expression and, therefore, highlights the social outcomes of the implementation gap.

\section{Lao Cai: the great expectations of a growing secondary city}

Located in the North-Western region of Vietnam, the province of Lao Cai covers an area of 6,375 sq.km combining highlands and lower areas, next to the Red River. Meanwhile, the eponymous city is by far the main urban center of the province, hosting 112,000 inhabitants on $228 \mathrm{sq} . \mathrm{km}$, according to the 2016 People's Committee statistical data. As everywhere in Vietnam, the definition of the "city" is quite broad and includes both urban wards (phuong, 12 in Lao Cai) and rural communes ( $x a, 5$ in Lao Cai), resulting in a relatively low average density of 491 people per sq.km. Hence, within its administrative boundaries, Lao Cai incorporates both the urban core and periurban areas, where farmlands and forest still occupy large portions of the land.

A particularity of Lao Cai is that the city was promoted to "grade II" in 2014. Vietnamese cities are classified in 4 urban grades (plus a "special urban grade" for Hanoi and Ho Chi Minh City) depending on their size and socio-economic characteristics. In theory, grade II cities have an urban population over 300,000 people, a high level of density in their urban core and less than $20 \%$ of their population working in agriculture. Therefore, to date, Lao Cai's demographic and economic characteristics (just over 100,000 inhabitants) technically meet grade III criteria rather than grade II. However, it is the responsibility of the Prime Minister to recognize which type of city gets categorized in grades II, I and special class. Hence, this 
DRAFT. G. Pulliat, The Implementation Gap. April 2018.

promotion clearly reveals the willingness of the national government to further and quickly develop Lao Cai as a major urban center.

This is described by an official at Lao Cai City People's Committee:

"There are several big cities in the eastern part of the country, but in the western side, there are few of them. This is why the government intends to further develop Lao Cai: it is meant to become the main center of the country, at the west of Hanoi." (Interview 19)

Additionally, this informant reports that the city is expected to become a grade I city by 2020 . He explains that this political choice is driven by two main factors:

- first, the desire of the government to have a well-developed border city in face the Chinese province of Yunnan and the city of Kunming, which is judged to be "much more developed" by the informant;

- second, the ambition to attract migrant workers from the surrounding areas to prevent them from migrating to Hanoi or Hai Phong, and thus to promote a more balanced urban development at the national scale.

Figure 2 Location Map: Northern Vietnam. Lao Cai as a port of entry to China.

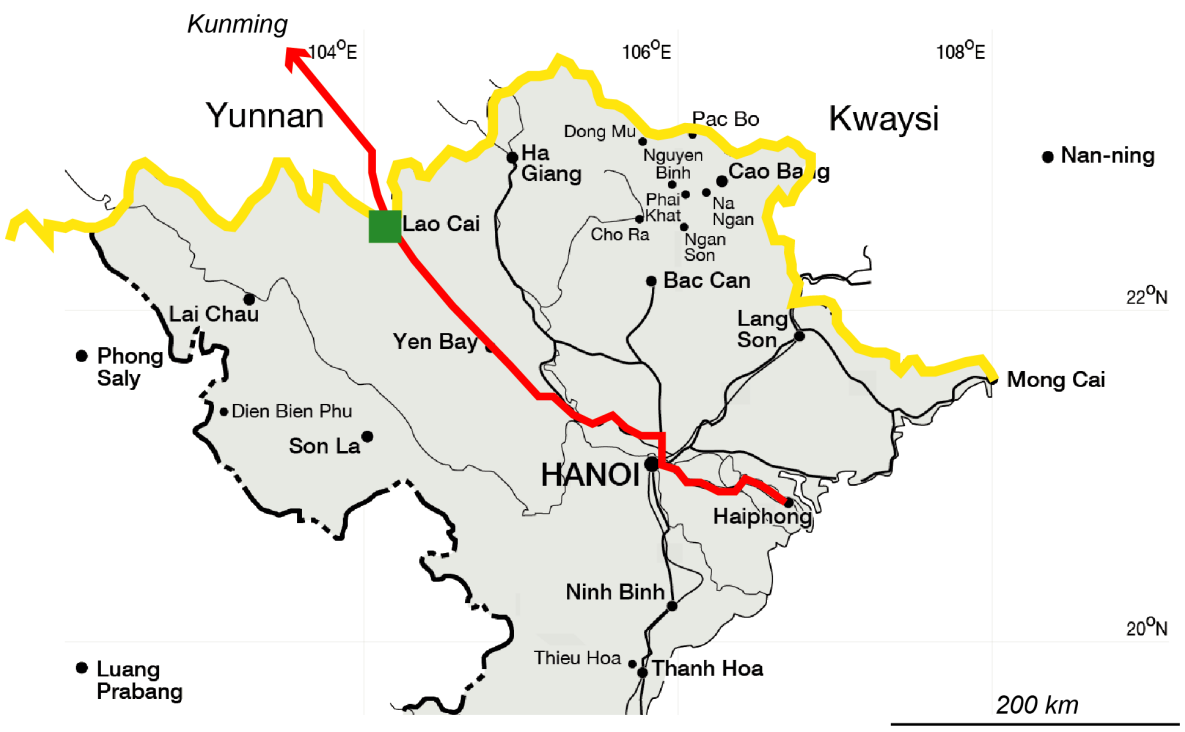

Vietnam-China border

Highway Haiphong-Hanoi-Lao Cai-Kunming

Therefore, the spatial expansion of Lao Cai city appears to primarily respond to a State-driven urban development pattern. This is quite unusual. In most Asian major cities, as a result of rapid demographic and economic growth, the demand for land drives a process of densification of the already urbanized areas, along with a sprawling urban development on the outskirts 
DRAFT. G. Pulliat, The Implementation Gap. April 2018.

of the city, whether planned or unplanned. In contrast, in Lao Cai, the supply of new urban land seems to precede the demand. The expansion of the city is primarily driven by the development of public urban projects: new infrastructure (roads, national bus station, new bridges, new border zone crossing and so on) and, for example, the new administrative ward along a new main axis (Tran Hung Dao Street)(cf. Figure 5 p.12). Lao Cai city has benefited from major government investments as well as from private investors over the last decade. In addition, an ambitious Master Plan has been adopted, emulating some of the principles of major cities.

The population is actually growing: from less than 100,000 in 2006, to 104,000 in 2011 and 112,000 in 2016. Between 2011 and 2016, the average growth rate of Lao Cai city reached $1.53 \%$ per year (see Figure 3 ). However, compared to the urban growth rate at the national level, this rate is not particularly singular: while the national population growth rate "only" reached around $1,08 \%$ per year over the same period, the growth rate of the national urban population hit $2.9 \%$ per year, e.g. almost twice as much as Lao Cai city.

Figure 3 Demographic growth rate. Data from the General Statistics Office and the Lao Cai city People's Committee annual report.

\begin{tabular}{|l|c|c|c|c|c|c|}
\hline & $\mathbf{2 0 1 2}$ & $\mathbf{2 0 1 3}$ & $\mathbf{2 0 1 4}$ & $\mathbf{2 0 1 5}$ & $\mathbf{2 0 1 6}$ & $\begin{array}{c}\text { average } \\
\text { (2012-2016) }\end{array}$ \\
\hline Lao Cai city & $1.97 \%$ & $1.69 \%$ & $1.16 \%$ & $1.24 \%$ & $1.61 \%$ & $\mathbf{1 . 5 3 \%}$ \\
\hline $\begin{array}{l}\text { Lao Cai } \\
\text { province }\end{array}$ & $1.49 \%$ & $1.45 \%$ & $1.42 \%$ & $1.40 \%$ & $1.45 \%$ & $\mathbf{1 . 4 4 \%}$ \\
\hline \begin{tabular}{l} 
Vietnam \\
\hline $\begin{array}{l}\text { Vietnam: urban } \\
\text { population }\end{array}$
\end{tabular} & $1.08 \%$ & $1.07 \%$ & $1.08 \%$ & $1.08 \%$ & $1.07 \%$ & $\mathbf{1 . 0 8 \%}$ \\
\hline
\end{tabular}

Moreover, the population growth seems to be lower than the rate of land conversion (Trincsi, Pham, and Turner 2014). However, the expected growth rate, as reported by the Climate Action Plan (cf. Figure 4), is much higher. Again, this suggests that the urban development pattern in Lao Cai is proactive, rather than reactive: the government aspires to foster a major city, further and faster than what the previous demographic growth trends would have produced. Hence, Lao Cai can be depicted as a secondary city benefiting from a voluntarist development policy emphasizing its urban core, as it is expected to become a major bridging point between Hanoi and China. 
DRAFT. G. Pulliat, The Implementation Gap. April 2018.

Figure 4 Lao Cai city's population. Source: M-BRACE project, Climate Action Plan For Lao Cai City, ISET-Vietnam, 2014, p11

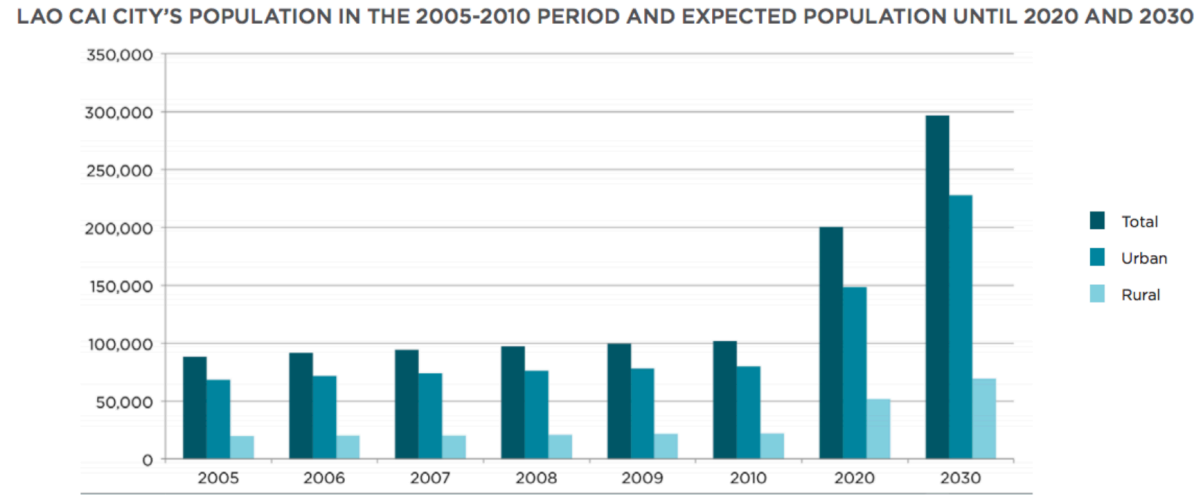

\section{The environmental protection policies and the bureaucracy: a failed governance}

Lao Cai province has long been identified as an ecological region of major importance in Vietnam, in particular for its forests. After decades of deforestation due to the lumber trade and agriculture expansion, among other factors (Roche and De Koninck 2002), the government has started to implement an afforestation policy, supported by the REDD+ program. Afforestation and improvement of the quality of forests are among the strategies identified in the National Strategy on Climate Change (Government of Vietnam 2011) to mitigate damage caused by natural disasters, preserve biodiversity and absorb greenhouse gases (Saavedra and Budd 2009). Therefore, environmental protection and climate change adaptation policies have been a key component of land use planning in Lao Cai province for at least two decades. More specifically, Lao Cai has adopted an Action Plan to Respond to Climate Change (Lao Cai core working group of M-BRACE project 2014), in collaboration with various international organizations. It envisions various actions to foster better adaptation to climate change, including raising awareness on the part of government officials, enhancing weather forecasting capacity, improving drainage capacity to reduce floods and upgrading the dyke system.

However, so far, the implementation of those policies seems to lack urgency, to say the least. A first indication is the prevalence of uneven implementation in different parts of the province. During my field work, some officials stated that the environmental protection policies are to be implemented in the rural parts of the province, beyond the city limits, rather than in Lao Cai city itself. This claim, however, does not meet the goals of 
DRAFT. G. Pulliat, The Implementation Gap. April 2018.

the stated policies. The city does contain protected forests, and does have risks management regulations, and the Action Plan itself is mainly focused on the city. The area of Lao Cai city also faces several environmental hazards, and they even may affect more people and infrastructure than in rural areas, considering the density of land occupation. Although the pressure on land use is, obviously, much stronger within the city limits than in the rest of the province, what happens in terms of environmental policies within these limits clearly illustrates the environmental governance of the whole province.

Overall, three major obstacles to an efficient implementation of environmental policies were identified through my research. First, the competing political goals and, in fine, the preeminence of economic growth over any environmental goal. Second, the deficiency in effectively enforcing the existing regulations. Third, a failure of governance in terms of environment-related actions.

\section{The preeminence of economic growth and economic development.}

As mentioned earlier, Lao Cai is the most important border city between Vietnam and China. Despite a long history of tensions and conflicts (Womack 2006), China is an essential economic partner of Vietnam, and these exchanges are reinforced by the agreements between China and ASEAN (Wong and Chan 2003). Hence, the national authorities consider it crucial to facilitate trade between the two countries; the opening of the highway between Hai Phong, Hanoi and Lao Cai (and going further to Kunming, see Figure 2) being a major milestone to this end. An informant from the Department of Urban Planning at the Province People's Committee details the benefit of this location for the city:

"The location is strategic. Lots of products from the United States or from Africa, for instance, are temporarily imported to Lao Cai on their way from Hai Phong to China, and are subsequently exported to China. The use of the road instead of the railway is much more efficient, and it provides high income from customs duty to Lao Cai." (Interview 5)

Moreover, as an emerging port of entry in the country and expected key hub in the North-Western province, particular attention has been paid to the shape and landscape of the city. The new planned wards are characterized by a large-scale urbanism. The new administrative ward along Tran Hung Dao street is an example of this particular form of development and consists of a large avenue lined with huge buildings on the top of hills, broad public places and monuments. Elsewhere, on-going and future projects include massive buildings along the river, malls, wider roads and even a 15,000-ha zone dedicated to logistics activities (across several districts in the province), an airport in Bao Hien, and a university campus, to name a few. This ostentatious urbanism, which symbolizes the State's ideology and aspirations (Moser 2010; Evers and Korff 2000), clearly aims at 
DRAFT. G. Pulliat, The Implementation Gap. April 2018.

demonstrating the "modernity" of the city (Leaf 2011; Labbé 2016; NguyenMarshall, Drummond, and Bélanger 2012). The latter being understood as planned, zoned, clean, and with no farmlands in the inner city, as stated by one of the informants from a ward People's Committee. This type of urbanism is highly resource-consuming and, thus, drives the remarkable pace of land consumption.

In this strategic context, the economic growth of the region seems to take hold over any other goal. An informant from the City People's Committee noted:

"Here, priority is given to the economic development. For instance, the mining activities are supported to this effect, although they are not sustainable." (Interview 21)

Mining is indeed a powerful example: a significant part of Lao Cai's economy is based on mineral resources, and their extraction has proven to be particularly damaging for the forests and to induce higher environmental risks (landslides, floods) (Lao Cai core working group of M-BRACE project 2014). But this economic goal is embedded in a national-wide socio-economic development planning, as explained by an informant from the Department of Construction in the City People's Committee:

"It is a matter of balance in the economic development among other things - because if we don't reinforce secondary cities, everyone will go to Hanoi or Hai Phong. The point of developing Lao Cai is for people to find jobs here, and to attract people from surrounding provinces." (Interview 19)

In this sense, the national urban planning policy aims to foster a national urban system where secondary cities, such as Lao Cai, attract local and regional migrating populations and provide adequate services for regional residents in support and complement to national major urban centers. Hence, although environmental issues are taken into account in the urban development policies, they are much less of a priority and should not affect the potential of economic growth. Central and local governments demonstrate a clear pro-growth orientation; environmental protection, if seen to conflict with economic interests, are subordinated to the later. Such a situation is often observed in other Asian cities and in China in particular (Lo and Leung 2000). This tension is made more explicit when observing how the environmental regulations are actually enforced. 
Figure 5 The new administrative ward in Lao Cai city: an example of ostentatious urbanism symbolizing the State's ideology and aspirations.

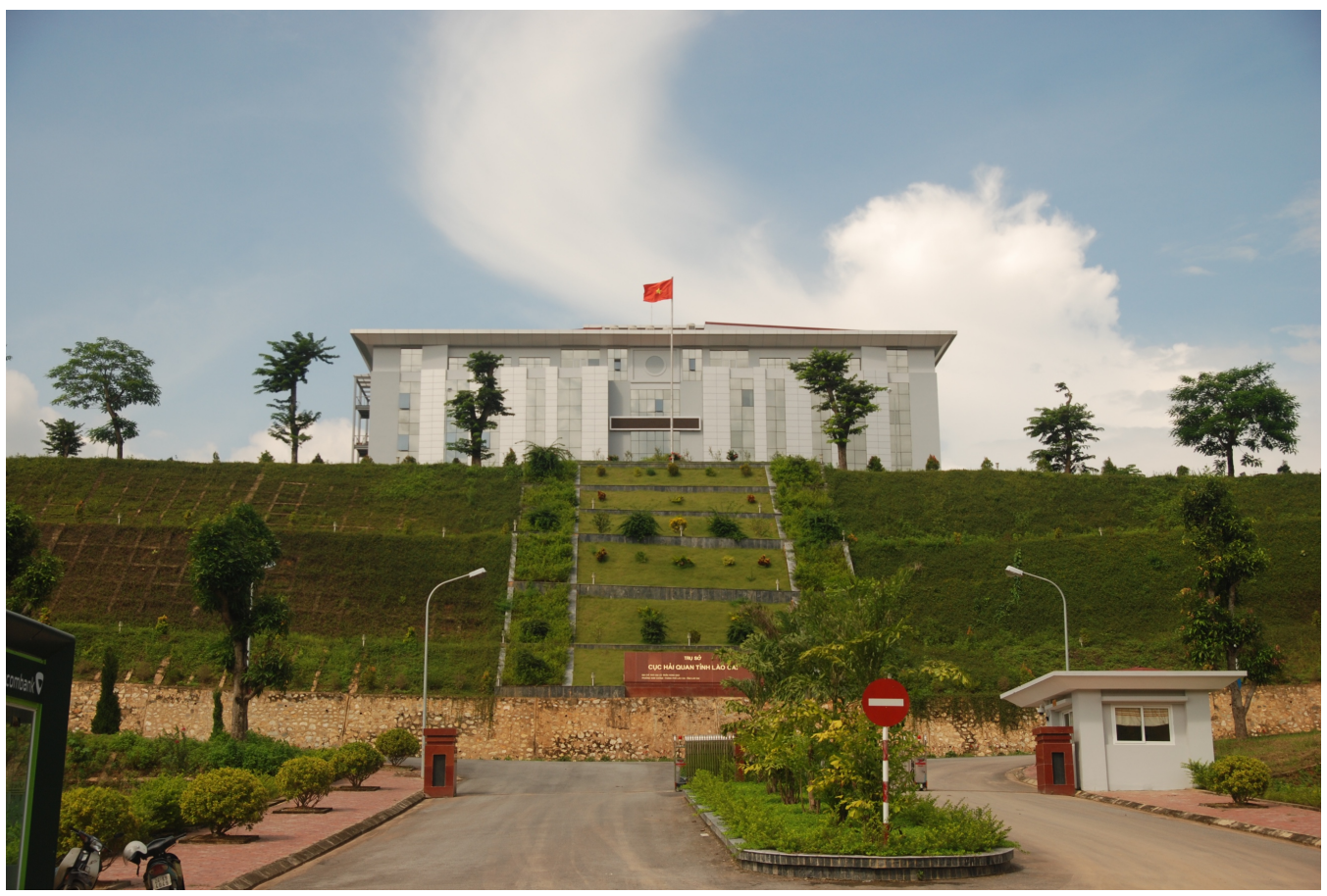

\section{The under-enforcement of existing regulations}

Lao Cai cannot be faulted for nonexistent environmental regulations: they do exist. For instance, two thirds of the forests within Lao Cai city ( 8,000 ha among 12,000 ha covered by forests) are protected, meaning that no conversion of land can occur, nor may mining or logging activities take place (those are permitted in the "economic forest"). Theoretically, a governmental decree protects most of the ricefields in Lao Cai city in order to secure a local rice supply. All projects requiring an approval from the Province People's Committee have to go through an environmental impact assessment, and they must include a plan to compensate for the ensuing environmental damages, if any. These represent only a couple of examples of environmental directives that were cited by respondents during the field research. However, some regulations remain to be applied at all: for instance, none of the respondents were able to identify the location of even one protected ricefield.

Furthermore, the enforcement of the existing regulations is flawed by the power relationships between decision-makers and applicants. Three informants specifically implicated the major companies in the construction sector, one of them detailing the case of the highly touristic township of Sapa: 
DRAFT. G. Pulliat, The Implementation Gap. April 2018.

"But there are different political interests behind all this. The big private companies have lots of influence, and money, and relationships with leaders, whether at the city level or the province level." (Interview 23)

"Sapa is a failure of Lao Cai. Nowadays, the natural landscapes are completely altered. Many investors come, and the chairmen of the local People's Committee are very happy to see them investing that widely in Sapa. (...) In Sapa, some urbanism regulations have been developed in collaboration with Aquitaine (a French organization working on construction legislation), but they are not observed: for instance, high and large buildings are under construction, although they are supposed to be forbidden. The development of Sapa is a mess. (...) The main building company has enough influence on political decisions to get their building permits no matter what. It is not good, it is not good for the development; but it is like that." (Interview 21)

When it comes to large-scale projects, the major companies are in an oligopolistic situation, and they somehow have the (unofficial) ability to negotiate the conditions of implementation of the projects and the regulations they will have to follow. These power relationships result in an under-enforcement, or a selective enforcement, of environmental laws. An informant in charge of the environmental impact assessment - a step that is regarded as a major tool to regulate the environmental cost of development projects - declared that it is rare for a project to be rejected due to its too high impact; however, they make sure that the plan of restoration is actually achieved, rather than set aside. To some extent, the environmental regulation is ex post, more than ex ante.

\section{The failure of the governance of the environmental policies}

Conducting interviews at almost all the levels of administration (the national level is missing in this study) has revealed the complexity of the decision-making, advocating, planning, implementation and assessment of the environmental policies. The role of each level is supposed to be formally determined, but in practice, a certain lack of clarity in responsibilities and duties prevails. In theory, as always in Vietnam, policy management is based on a straight-forward top-down procedure: the decisions are made at the higher level and lower levels apply or enforce these decisions ( $c f$. Figure 6). In practice, one observes that it leads to a somewhat confused implementation and a dilution of responsibilities. 
DRAFT. G. Pulliat, The Implementation Gap. April 2018.

Figure 6 A top-down governance
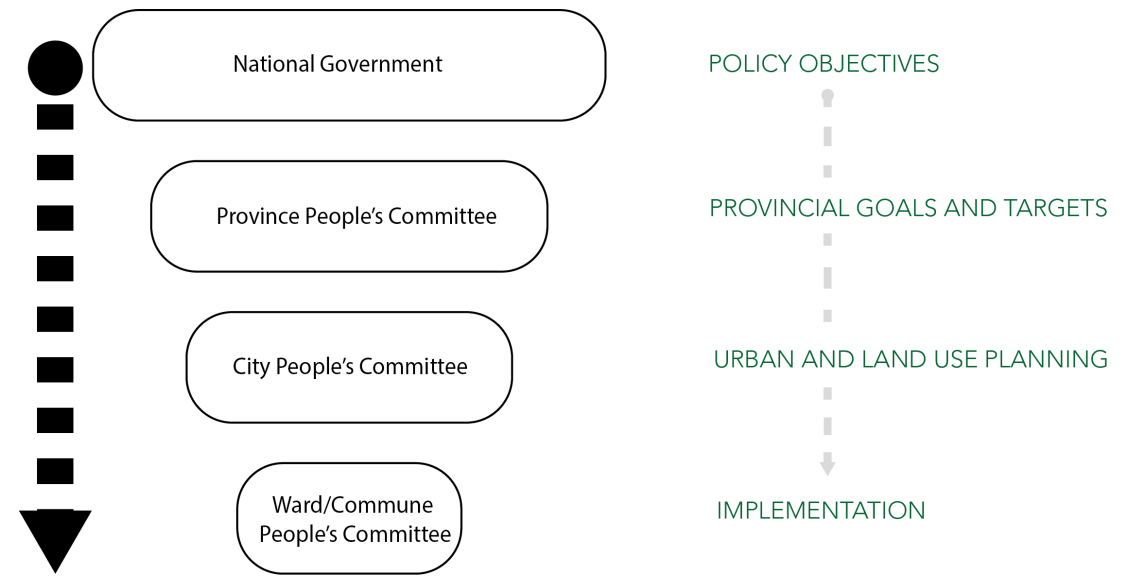

Indeed, at the upper levels, officials (such as from Department of Natural Resources and the Environment, Department of Urban Planning, Department of Construction) reminded me that they determine general objectives, provide guidance to lower levels, and assess the reports on activities, but the implementation of environmental policies itself is the local authorities' responsibility. At the local level, however, it is less clear which department of the People's Committee is in charge of the implementation of those policies, as they do not necessarily have a specific bureau for the environment, and other departments are not always aware of the environmental policies (for instance, at the local level, most of the respondents had never heard about the Action Plan for Climate Change Adaptation before). In one of the target wards, a respondent from the Bureau for Land Use declared that:

"To date the local People's Committee does not have a civil servant attached to the environmental issues." (Interview 7)

Due to limited budget and competing priorities, environmental monitoring and climate policy advocacy at the local scale remain scarce. In addition, the perception of environmental policies at the local level is narrower than that at the province scale, and typically more focused on local challenges rather than the global ones. For instance, at the local level, the intial meaning of "environmental policy" is linked to waste management and local pollution rather than the climate change adaptation, risk management or environmental protection (in a broader sense) policies. Typically, as in Van Hoa, when asked to respond to the question "What are the issues posed by climate change in this ward?", a respondent in charge of the land use management replied:

"So far I have not experienced a notable change in the climate. But anyway, there is not too much pollution here, it is not an issue in this ward. There is no industrial zone or such things, so we do not need any specific policy against pollution." (Interview 7) 
DRAFT. G. Pulliat, The Implementation Gap. April 2018.

At the city scale, a respondent reported that, "the city People's Committee really tries hard to protect the environment", and illustrated her point further by continuing, "the solid waste management is a good example" (as the city has built a major waste management unit). This observation suggests that environmental challenges perceived by the officials depend on their scope of action, and that there is a discrepancy between the national goals and the local actions in the field of environmental policies. It does not mean that they do not fit together, but that the relative priority might be different. This is reinforced by the difference in time scale: the impacts of climate change are considered as long-term ones by local stakeholders, while local environmental challenges, such as waste management, are considered more urgent.

Nevertheless, it is noticeable that, when asked about the environmental policies, local officials state that they only execute decisions enacted at the upper level and cannot make any other policy. At the city level, when discussing about the land use planning and the protection of land in accordance to the Action Plan for Climate Change Adaptation, an informant from the office for agriculture replied:

\section{"Regarding urban planning, it cannot be changed [hence there is no way to apply the Action Plan recommendations] because it has already been decided." (Interview 18)}

The same statement was made by several other respondents: the need to wait until the provincial planning, or even the national environmental regulations, are revised before implementing environmental policies further and incorporating those goals into other fields (such as land use and construction). At the province level, when investigating the outcomes and assessment of those policies (regarding land use, forest protection and hazard prevention), the most common answer was: "There are reports from local People's Committees". None of the respondents were either able or willing to precisely assess the actual implementation of the provincial directions in the environmental field.

Interestingly, the lack of capacity for implementation was recognized by various respondents. As for the Action Plan for Climate Change Adaptation, for instance, an official from the Office for the Environmental Protection at the Province People's Committee explained that the ward and communes' People's Committees were in charge of its implementation, but that they were doing it "according to their own possibilities". The informant believes that the wards lack adequate financial resources to actually do what is expected in the plan, so they have to adjust their actions according to their means. Another official from the Department of Natural Resources and the Environment at the Province People's Committee recognizes that:

"the Action Plan for Climate Change Adaptation has been adopted quite a long time ago already, but it not clearly feasible to prevent climate change. I try my best to include the recommended actions into as many projects as possible to 
DRAFT. G. Pulliat, The Implementation Gap. April 2018.

\section{prevent climate change, but it is still rather limited." (Interview}

13)

At some point, the extent to which environmental policies are actually implemented depends on the goodwill and the involvement of the executants. Hence, increasing the involvement of local stakeholders in the climate adaptation monitoring seems critical to actual effective implementation (Danielsen et al. 2010).

Finally, it seems that the gap between the declared goals in terms of climate adaptation and environmental protection on the one hand, and the actual implementation of such policies on the other hand, is substantial and often acknowledged by policy-makers themselves. However, the bureaucracy fails to address the gap because of disconnected policies and competing goals where the short-term economic outcomes are given priority. In addition, despite the broad awareness regarding specific issues, such as the forest degradation, appreciation of the challenges posed by climate and environmental changes seems to be partial. As long as there is no significant pollution issue (as in industrial zones, for example), most of policy-makers and other executants consider those challenges as subordinate and/or out of their reach. This is quite consistent with Tong's observation in secondary cities in China (Tong 2007), where the author found that policy-makers are reluctant to implement environmental policies if they might affect economic growth, until a higher pollution level is reached, influencing their policy preferences.

\section{The uses of land: a spatial expression of the hiatus between urbanization and risks mitigation}

What are the consequences of those failures in environmental governance on the ground? How do those policies affect the uses of land? To investigate the implementation of environmental policies in Lao Cai, the focus of the field work also took place at a very detailed scale to shed light on the patterns of land use in the outskirts of the city and, thus, reveal the interplay between the various planning policies. In this respect, the commune of Van Hoa and the ward of Xuan Tang are quite similar: they are experiencing a substantial shift in land use, their population is expected to rise and, at the same time, they face diverse environmental hazards.

Located at the urban fringe of Lao Cai (see Figure 1 p.4), the two wards are undergoing a rapid urban transition. Major infrastructure works are under construction, the most important ones at the time of the study being the new set of local and provincial roads (Xuan Tang is located near the new Lao Cai bus station and the point of entry of the highway) and the river embankment system. These require massive consumption of land and, 
DRAFT. G. Pulliat, The Implementation Gap. April 2018.

specifically, farmlands. In Van Hoa, among the 11 thon (the administrative neighborhoods of a commune), 10 are expected to be urbanized by 2020, and only one will still comprise space dedicated to farmlands. The process has started already and, to date, farmlands remain in only 5 thon. Forests, which represent a significant part of the land use, are partly protected and considered a tool to contribute to the "ecological quality" of the ward; meanwhile, farmlands are widely considered a land reserve for future urban sprawl. In Xuan Tang, an official from the Office for the Land Use Management explained that the local People's Committee seizes farmlands prior to having a specific urban development project, so as to prepare a land reserve for future urbanization projects. Hence, the pace of change in land use from agricultural to urbanized land is high and expected to remain high. This observation is quite typical in the outskirts of growing secondary cities (Rimmer and Dick 2009; Schneider and Mertes 2014); however, in the specific case of Lao Cai, it begs a major question: in an environment wellknown for its exposure to various hazards, what are the impacts of these land use changes in terms of risks?

The question of risk management is not missing in the land use planning. The interviews with officials in Lao Cai city and province suggest there are two main approaches to address risks:

- a technical one, emphasizing the development of infrastructure, such as dams and dykes to prevent floods and landslides;

- a socio-spatial one, where people exposed to hazards (mostly flood and landslides) are encouraged to move away and relocate in less-exposed areas.

The technical approach aims at influencing the magnitude of hazards when they occur, whereas the socio-spatial one focuses on decreasing the exposure. Hence, the risk management approach in Lao Cai aims at reducing vulnerability to hazards by taking action to improve the coping capacity and to reduce the potential damages.

However, the implementation of such risk management does come with questions. The first one relates to the interplay between the hazards and the urbanization process of the area; the second one points to the consequences in terms of vulnerability of residents' relocation.

\section{Incorporating risks consideration into urban planning: a limited achievement}

During my field work, a divergence appeared between the awareness about the need for risk mitigation on the one hand, and the actual uses of land on the second. While major infrastructures are under construction to mitigate the impact of hazards, such as an embankment system to prevent floods, the rest of the urban development does not seem to address local risks. For instance, an official from the Department of Construction at the province People's Committee detailed that the construction of roads requires some digging on the mountains, which increases the risk of landslides. According 
to him, building tunnels would avoid the additional risk, but Lao Cai cannot afford this process.

Afforestation is a major environmental target of the province, but mining activities occur in economic forests and they increase the risk of landslides. The respondents in charge of the Department of Construction explain that, while risk assessments are required prior to getting a building permit, local infrastructures do not differ from elsewhere and, thus, do not specifically address the higher risks, nor do they strengthen climate resilience in the long run. They mention the road system as an example: the new roads regularly flood during heavy rains. In addition, the infrastructures that are built specifically to mitigate the risk of flooding, such as the dykes, may induce higher risks in the future. The embankment project is clearly contributing to the urbanization of the river bank, where the land used to be dedicated to agriculture (and is prone to erosion). The ability of the urbanized land to absorb excess water is obviously lower than that of agricultural land; therefore, while the level of the ground is higher, the risk of flooding in the future urbanized area in case of major floods seems high. This speculation is also supported by the limited control that Lao Cai authorities have over the river; the main dams upstream are controlled by China, and therefore the regulation of the water flows somewhat depends on the geopolitical situation between the two countries. Overall, the construction of infrastructures and the urban development of Lao Cai may have ambiguous effects on the risk that the city faces.

\section{Figure 7 Urbanizing the Red River banks}

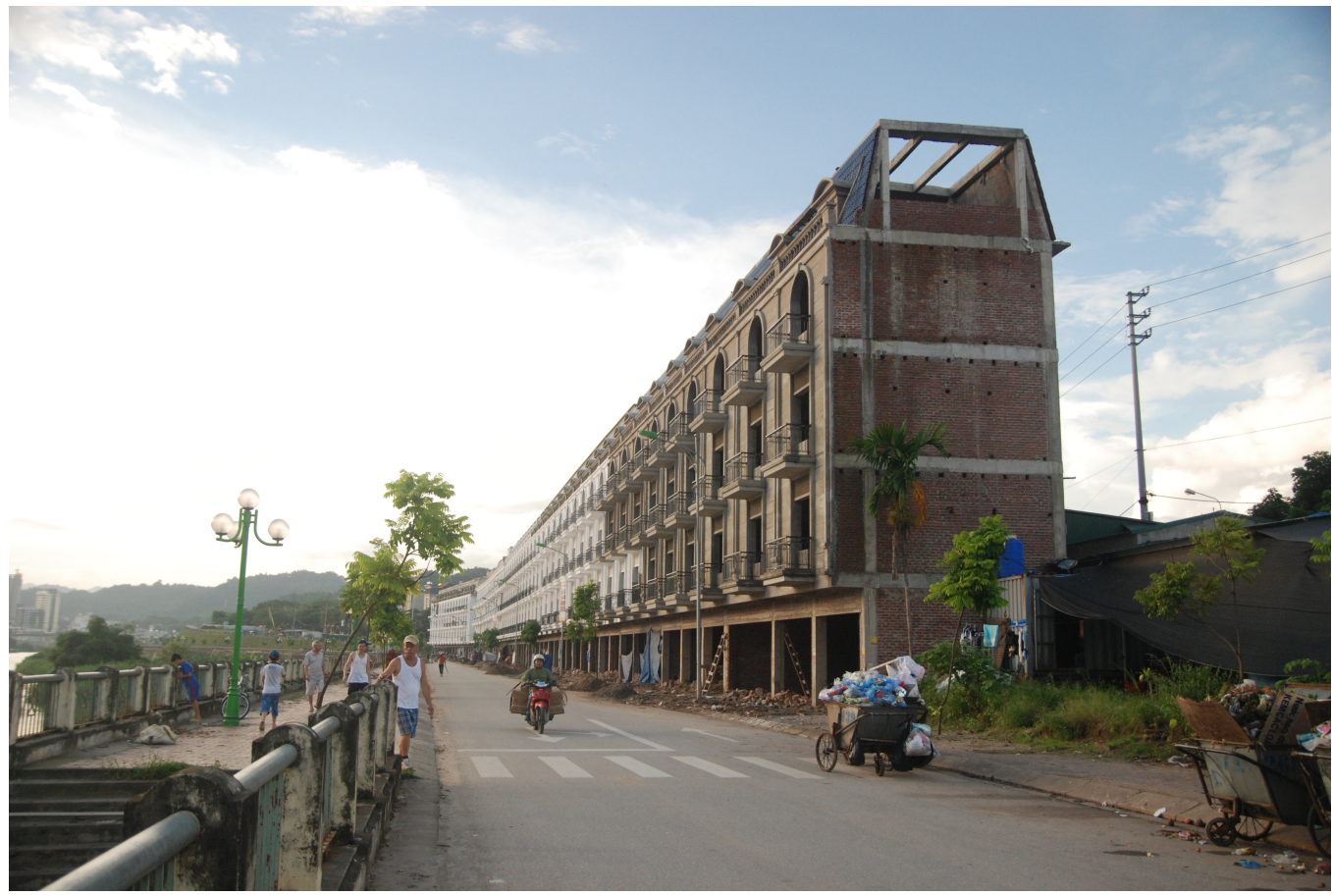


DRAFT. G. Pulliat, The Implementation Gap. April 2018.

\section{Reducing vulnerability by relocating dwellers: at what cost?}

In such a risky environment, the risk management policy primarily addresses the consequences of hazards, with funding for and support to victims. But this policy is also reactive and planners expect to relocate the residents living in the most exposed areas, such as on the hills prone to landslides and the river bank with no embankment system. An interviewee explained that these residents are encouraged to move and may receive financial support to build a house in a relocation ward. For instance, in Xuan Tang, most of the residents, who were scattered across the ward, are being relocated into the "new ward", both to prepare a land fund for urbanization and to reduce their exposure to floods and landslides. The relocation ward is located further from the River and some surfacing works were completed around the area to reduce the risk of landslide.

However, this relocation and land seizure process also results in a transition in terms of livelihoods. Those residents, who get a financial compensation and can relocate to the new ward, lose their farmlands and, therefore, one of their sources of income. This is a major issue in Lao Cai, as well as in the outskirts of most of the expanding cities in Vietnam (Labbé and Musil 2014; Phuc, Westen, and Zoomers 2014). The State has the ability to expropriate people, in particular their farmlands, and uses this ability to reshape the uses of land (Hansen 2013; Labbé 2016). Meanwhile, the level of compensation is decided by the provincial authorities, depending on the kind of land, production, location, duration of ownership and so on. The challenges are twofold:

- First, the idea that compensation amounts are too low is widespread. In Lao Cai, both residents and officials at the ward and city levels, expressed this opinion, and some mentioned values from other provinces where the compensations ended up being higher. Although the two investigated wards have not seen any major protest or mobilization, this situation fuels the feeling that local residents are the losers from the urban transition (and the winners are the investors who take part in the new urban development projects) ${ }^{4}$.

- The second challenge relates to the shifts in livelihoods. All the respondents, with no exception, mentioned this urban shift as the main issue that the wards were facing and will face with the continuation of expropriation patterns. It is worth noting that farmers in the outskirts of the city, settled on plots of land exposed to various hazards, were identified as among the most vulnerable groups to climate change in Lao Cai (Lao Cai core working group of M-BRACE project 2014). Hopefully, their relocation will result in a decreased vulnerability to climate change and environmental hazards. However, finding a new secure source of income is reported to be difficult. Most of the respondents (either residents or officials)

4 This perception of rising inequalities due to development projects is similar to what was observed in Ninh Binh in chapter $\mathrm{x}$ of this book. 
DRAFT. G. Pulliat, The Implementation Gap. April 2018.

consider the vocational training offered by the People's Committee as ineffective. Again, this is typical across Vietnam in general; therefore, expropriated farmers rely on their own network to develop a new economic activity, often in services (such as preparing meals for ceremonies in Xuan Tang) or industry. Several elderly residents did not convert to a new job and keep up with farming, on very limited plots of land where they have been relocated (e.g., in the garden of their new house). The interviewed residents often considered those new livelihoods to be more insecure than farming, because they are often short-term activities, they may require to be mobile, and the income is sometimes considered unstable.

Therefore, the changes in the uses of space seems to increase the level of uncertainty: uncertainty regarding the occurrence of hazards, their magnitude and location, and uncertainty regarding the socio-economic environment and the available resources. The changes in land uses reshapes the vulnerability map and patterns experienced by residents of Lao Cai.

\section{Managing environmental risks in an authoritarian context}

Based on two sets of interviews conducted at various scales, this study allows me to explore the nexus between environmental planning and the outcomes for local residents. While the scope of this study remains limited and further explorations are necessary to quantitatively assess the impact of displacements on residents' livelihoods, as well as the potential costs for residents of hazards occurring across the city, it highlights some challenges that are often purposely disregarded by upper-scale officials. Indeed, interviewed residents mentioned the public meetings that are held by local authorities to provide information about future planning projects, but they also stressed that their concerns were barely heard. Most respondents declared that they had limited capacity to affect what had been decided by public authorities, so they have to cope and adjust. When I reported residents' concerns about their livelihoods and access to land during interviews with officials at the city and provincial scales, I was answered twice a firm and optimistic: "they will adapt". This picture is another reminder of the authoritarian nature of the Vietnamese state. Among planning tools, the displacement of people is an option that relatively easy to use since the contestation against political decisions is weak and the institutionalized civil society is limited (Thayer 2009; Kerkvliet 2003).

In response to the clear need to reduce vulnerability to current and expected hazards, national and local authorities have developed both incentives and coercive legal tools to reorganize the occupation of land within planned zones ${ }^{5}$, and they used them extensively. But these practices raise concerns about the social outcome of such policies. During the interviews, several respondents from the People's Committees mentioned that many

${ }^{5}$ It is worth noting that population resettlements are not new: resettlement programs have been broadly used by the Communist Party both at national and local scales since its accession to power (Jones and Fraser 1982). 
DRAFT. G. Pulliat, The Implementation Gap. April 2018.

groups from ethnic minorities, who are typically marginalized (Turner $2012 \mathrm{~b}, 2012 \mathrm{a}$ ), were particularly vulnerable to hazards, due to their location, and that they were incentivized to move. For those groups, as well as for the farmers described earlier, the displacement comes with a shift in livelihoods which is neither easy (as they typically have limited resources) nor desired. Is it fair to make them carry the cost of adaptation? Moreover, while the relocation reduces the exposure on the short term to current hazards, the outcome is less clear when it comes to future hazards. As a result of climate change, the magnitude and frequency of future hazards is expected to be higher, and the potential damages may be much more severe since they will occur in more urbanized and more densely populated areas. Does this relocation policy reduce vulnerability or, rather, increase overall uncertainty?

\section{Conclusion: the implementation gap, a case for future activism?}

Over the past decade, Vietnam has started to develop a significant body of policies and regulations to tackle climate change. However, beyond noble intentions, a closer look the into implementation process and its results on the ground reveals a contrasting reality. Despite its substantial power based on a proven top-down policy-making, the Vietnamese state faces significant flaws in its environmental governance that result in a nationalto-local disconnect. Yet, this disconnect is not rooted in a lack of knowledge or awareness. As Mitchell and Laycock (2017) have observed in the Philippines, the need for climate adaptation is actually widely acknowledged among policy makers, practitioners and residents. But competing urban development priorities result in a failure to prioritize climate change adaptation. Similar to every environmental issues in Vietnam and for biodiversity loss, in particular (Ortmann 2017), a striking awareness-topractice disconnect is observed.

In this regard, a specific complication for secondary cities is that they have contradictory goals: preserving their environment and promoting a climate resilient urban planning, but also absorbing a significant part of the demographic growth to prevent further sprawl of megacities, with limited financial and technical capacities. In addition, in Vietnam, the authoritarian, centralized political organization limits the capacity of local stakeholders to adopt local regulations and therefore delays even more the implementation of national guidelines (Urwin and Jordan 2008).

Hence, to the core question of this paper, i.e. whether the political rhetoric around climate change and the emphasize put on environmental policies have impacted the local urban planning, the answer leans toward the negative side. While emphasis on risks management is noticeable in planning practices, climate adaptation and environmental protection policies are far from being implemented effectively. There is an 
DRAFT. G. Pulliat, The Implementation Gap. April 2018.

implementation gap that results in a hiatus between a pro-climate adaptation discourse and the actual planning that seems to follow the "business as usual" pattern. Moreover, the options chosen by local bureaucrats, among which people's displacements, put a great pressure on local residents' livelihoods while having ambiguous outcome on long-term climate vulnerability. Are risk management policies actually a rationale to increase the control over population and force the transition towards a desired urban, so-called "modern" society?

In a country facing recurrent major environmental crises, where the cost of "natural" disasters is rapidly increasing to reach an estimated 60 trillion VND in 2017 (US\$2.6 billion) and where 386 people were reported dead and missing from such events on the same year (Viet Nam News 2017), the question of the implementation of environmental policies becomes crucial. While the institutional channel gives limited voice to the general public and civil society, the rising public concern around pollution and environmental destruction, as well as the growing contestation against expropriations, might be the seeds of change. Large protests around environmental issues have started to occurred, for instance in 2016 after toxic industrial discharge that resulted in tons of dead fish along the Vietnam's central coastline (Hutt 2017). At least, for now, the environment has become a sensitive political topic.

\section{References}

Adger, W.Neil. 2001. "Scales of Governance and Environmental Justice for Adaptation and Mitigation of Climate Change." Journal of International Development 13 (7): 921-31. https://doi.org/10.1002/jid.833.

Amin, Ash, and Stephen Graham. 1997. "The Ordinary City." Transactions of the Institute of British Geographers 22 (4): 411-29. https://doi.org/10.1111/j.0020-2754.1997.00411.x.

Anguelovski, Isabelle, and JoAnn Carmin. 2011. "Something Borrowed, Everything New: Innovation and Institutionalization in Urban Climate Governance." Current Opinion in Environmental Sustainability 3 (3): 169-75. https://doi.org/10.1016/j.cosust.2010.12.017.

Asif, Furqan, Melissa Marschke, and Chanrith Ngin. 2017. "Assessing the Potential of a LowCarbon Future for Cambodia." Journal of Renewable and Sustainable Energy 9 (2). https://doi.org/10.1063/1.4978495.

Berrang-Ford, Lea, James D. Ford, and Jaclyn Paterson. 2011. "Are We Adapting to Climate Change?" Global Environmental Change 21 (1): 25-33. https://doi.org/10.1016/j.gloenvcha.2010.09.012.

Birkmann, Jörn, Matthias Garschagen, Frauke Kraas, and Nguyen Quang. 2010. “Adaptive Urban Governance: New Challenges for the Second Generation of Urban Adaptation Strategies to Climate Change." Sustainability Science 5 (2): 185-206. https://doi.org/10.1007/s11625010-0111-3.

Chan, Hon S., Koon-kwai Wong, K. C. Cheung, and Jack Man-keung Lo. 1995. "The Implementation Gap in Environmental Management in China: The Case of Guangzhou, Zhengzhou, and Nanjing." Public Administration Review 55 (4): 333-40. https://doi.org/10.2307/977124.

Danielsen, Finn, Neil D. Burgess, Per M. Jensen, and Karin Pirhofer-Walzl. 2010. "Environmental Monitoring: The Scale and Speed of Implementation Varies According to the Degree of 
DRAFT. G. Pulliat, The Implementation Gap. April 2018.

Peoples Involvement." Journal of Applied Ecology 47 (6): 1166-68. https://doi.org/10.1111/j.1365-2664.2010.01874.x.

Dupuis, Johann, and Peter Knoepfel. 2013. "The Adaptation Policy Paradox: The Implementation Deficit of Policies Framed as Climate Change Adaptation.” Ecology and Society 18 (4). https://doi.org/10.5751/ES-05965-180431.

Evers, Hans-Dieter, and Rüdiger Korff. 2000. Southeast Asian Urbanism: The Meaning and Power of Social Space. LIT Verlag Münster.

Government of Vietnam. 2011. National Strategy on Climate Change. http://chinhphu.vn/portal/page/portal/English/strategies/strategiesdetails\%3FcategoryId \%3D30\%26articleId\%3D10051283.

Hansen, Kaitlin. 2013. "Land Law, Land Rights, and Land Reform in Vietnam: A Deeper Look into 'Land Grabbing' for Public and Private Development." Independent Study Project (ISP) Collection, October. http://digitalcollections.sit.edu/isp_collection/1722.

Hunt, Alistair, and Paul Watkiss. 2011. "Climate Change Impacts and Adaptation in Cities: A Review of the Literature." Climatic Change 104 (1): 13-49. https://doi.org/10.1007/s10584010-9975-6.

Hutt, David. 2017. "Will the Environment Be the Vietnam Government's Downfall?" The Diplomat, March 22, 2017. https://thediplomat.com/2017/03/will-the-environment-be-the-vietnamgovernments-downfall/.

ICLEI. 2017. "Resilient Cities Report 2017: Tracking Local Progress on the Resilience Targets of SDG 11.” https://resilientcities2018.iclei.org/wpcontent/uploads/2017/11/RC2017_Report_Online_26102017_Final-compressed.pdf.

Jones, G.W., and S.E. Fraser. 1982. "Population Resettlement Policies in Vietnam." In Population Resettlement Programs in Southeast Asia, edited by G.W. Jones and H.V. Richter, 11333. Development Studies Centre Monograph. Development Studies Centre, Australian National University. https://www.popline.org/node/422448.

Kerkvliet, Ben JT. 2003. "Authorities and the People: An Analysis of State-Society Relations in Vietnam." In Postwar Vietnam: Dynamics of a Transforming Society, edited by Hy Van Luong, 27. Singapore: Institute of Southeast Asian Studies / Rowman \& Littlefield publishers.

Labbé, Danielle. 2016. "Critical Reflections on Land Appropriation and Alternative Urbanization Trajectories in Periurban Vietnam." Cities 53 (April): 150-55. https://doi.org/10.1016/j.cities.2015.11.003.

Labbé, Danielle, and Clement Musil. 2014. "Periurban Land Redevelopment in Vietnam under Market Socialism." Urban Studies $51 \quad$ (6): 1146-61. https://doi.org/10.1177/0042098013495574.

Lao Cai core working group of M-BRACE project. 2014. "Climate Action Plan for Lao Cai City Responding to Climate Change from 2014-2020 and Visioning to 2030." Institute for Social and Environmental Transition-International.

Leaf, Michael. 2011. "Periurban Asia: A Commentary on “Becoming Urban.” Pacific Affairs 84 (3): 525-34. https://doi.org/10.5509/2011843525.

Lo, Carlos Wing Hung, and Sai Wing Leung. 2000. "Environmental Agency and Public Opinion in Guangzhou: The Limits of a Popular Approach to Environmental Governance<a Href="\#fn01">*</A>." The China Quarterly 163 (September): 677-704. https://doi.org/10.1017/S0305741000014612.

Mitchell, Carrie, and Katherine Laycock. 2017. "Planning for Adaptation to Climate Change: Exploring the Climate Science-to-Practice Disconnect." Climate and Development, December, 1-9. https://doi.org/10.1080/17565529.2017.1411243.

Mol, Arthur P. J. 2009. "Environmental Governance through Information: China and Vietnam." Singapore Journal of Tropical Geography 30 (1): 114-29. https://doi.org/10.1111/j.14679493.2008.00358.x

Moser, Sarah. 2010. "Putrajaya: Malaysia's New Federal Administrative Capital." Cities 27 (4): 285-97. https://doi.org/10.1016/j.cities.2009.11.002.

Neil Adger, W. 1999. "Social Vulnerability to Climate Change and Extremes in Coastal Vietnam." World Development 27 (2): 249-69. https://doi.org/10.1016/S0305-750X(98)00136-3.

Nguyen-Marshall, Van, Lisa B. Welch Drummond, and Danièle Bélanger, eds. 2012. The Reinvention of Distinction. Modernity and the Middle Class in Urban Vietnam. Dordrecht: Springer. https://doi.org/10.1007/978-94-007-2306-1.

Nhan Dan. 2017. "Tropical Low Depression Brings Heavy Rain, Flooding to Northern and Central Regions." Nhan Dan Online, October 2017. http://en.nhandan.com.vn/society/item/5559802-tropical-low-depression-brings-heavyrain-flooding-to-northern-and-central-regions.html. 
DRAFT. G. Pulliat, The Implementation Gap. April 2018.

Ortmann, Stephan. 2017. Environmental Governance in Vietnam: Institutional Reforms and Failures. Springer.

Phuc, Nguyen Quang, A. C. M. van Westen, and Annelies Zoomers. 2014. "Agricultural Land for Urban Development: The Process of Land Conversion in Central Vietnam." Habitat International 41 (January): 1-7. https://doi.org/10.1016/j.habitatint.2013.06.004.

Puppim de Oliveira, Jose A. 2013. "Learning How to Align Climate, Environmental and Development Objectives in Cities: Lessons from the Implementation of Climate CoBenefits Initiatives in Urban Asia." Journal of Cleaner Production, Special Volume: Climate Co-Benefits in Urban Asia, 58 (November): 7-14. https://doi.org/10.1016/j.jclepro.2013.08.009.

Rimmer, Peter James, and Howard W. Dick. 2009. The City in Southeast Asia: Patterns, Processes and Policy. NUS Press.

Roberts, Brian, and Peter Hohmann. 2014. "The Systems of Secondary Cities - The Neglected Drivers of Urbanising Economies.” CIVIS Series. Cities Alliance. http://documents.worldbank.org/curated/en/400881468181444474/pdf/898610BRI0CIVI0 0Box385295B00PUBLIC0.pdf.

Robinson, Jennifer. 2006. Ordinary Cities: Between Modernity and Development. Psychology Press.

Roche, Yann, and Rodolphe De Koninck. 2002. "Les enjeux de la déforestation au Vietnam." VertigO - la revue électronique en sciences de l'environnement, no. Volume 3 Numéro 1 (April). https://doi.org/10.4000/vertigo.4113.

Ryan, Daniel. 2015. "From Commitment to Action: A Literature Review on Climate Policy Implementation at City Level." Climatic Change 131 (4): 519-29. https://doi.org/10.1007/s10584-015-1402-6.

Saavedra, Casilda, and William W. Budd. 2009. "Climate Change and Environmental Planning: Working to Build Community Resilience and Adaptive Capacity in Washington State, USA." Habitat International, Climate Change and Human Settlements, 33 (3): 246-52. https://doi.org/10.1016/j.habitatint.2008.10.004.

Schneider, A., and C. M. Mertes. 2014. "Expansion and Growth in Chinese Cities, 1978-2010." Environmental Research Letters 9 (2): 024008. https://doi.org/10.1088/1748. 9326/9/2/024008.

Thayer, Carlyle A. 2009. "Vietnam and the Challenge of Political Civil Society." Contemporary Southeast Asia: A Journal of International and Strategic Affairs 31 (1): 1-27.

Tong, Yanqi. 2007. "Bureaucracy Meets the Environment: Elite Perceptions in Six Chinese Cities." The China Quarterly 189 (March): 100-121. https://doi.org/10.1017/S0305741006000828.

Trincsi, Kate, Thi-Thanh-Hiên Pham, and Sarah Turner. 2014. "Mapping Mountain Diversity: Ethnic Minorities and Land Use Land Cover Change in Vietnam's Borderlands." Land Use Policy 41 (Supplement C): 484-97. https://doi.org/10.1016/j.landusepol.2014.06.022.

Turner, Sarah. 2012a. "Making a Living the Hmong Way: An Actor-Oriented Livelihoods Approach to Everyday Politics and Resistance in Upland Vietnam." Annals of the Association of American Geographers 102 (2): 403-422.

2012b. "Forever Hmong': Ethnic Minority Livelihoods and Agrarian Transition in Upland Northern Vietnam." The Professional Geographer 64 (4): 540-53. https://doi.org/10.1080/00330124.2011.611438.

Urwin, Kate, and Andrew Jordan. 2008. "Does Public Policy Support or Undermine Climate Change Adaptation? Exploring Policy Interplay across Different Scales of Governance." Global Environmental Change 18 (1): 180-91. https://doi.org/10.1016/j.gloenvcha.2007.08.002.

Viet Nam News. 2017. "2017 Plagued by Devestating Natural Disasters." Vietnamnews.Vn, December 30, 2017. http://vietnamnews.vn/society/420360/2017-plagued-by-devestatingnatural-disasters.html.

VNS. 2016. "10 People Swept Away in Lào Cai Flood.” Viet Nam News, May 8, 2016. http://vietnamnews.vn/society/300716/10-people-swept-away-in-lao-cai-flood.html.

—. 2017. "Heavy Rains Wreak Havoc in Lào Cai." Viet Nam News, September 28, 2017. http://vietnamnews.vn/society/394625/heavy-rains-wreak-havoc-in-laocai.html\#Dy6tMXwgsIwE19Q2.97.

Womack, Brantly. 2006. China and Vietnam: The Politics of Asymmetry. Cambridge; New York: Cambridge University Press.

Wong, John, and Sarah Chan. 2003. "China-Asean Free Trade Agreement: Shaping Future Economic Relations.” Asian Survey 43 (3): 507-26. https://doi.org/10.1525/as.2003.43.3.507.

Yusuf, Arief Anshory, and Herminia Francisco. 2009. "Climate Change Vulnerability Mapping for Southeast Asia.” https://idl-bnc-idrc.dspacedirect.org/handle/10625/46380. 